\title{
ASSOCIAÇÕES, PARTICIPAÇÃO E REPRESENTAÇÃO: COMBINAÇÕES E TENSÕES
}

LÍGIA HELENA HAHN LÜCHMANN

Conjugando o debate sobre formas alternativas de representação política com estudos que analisam as contribuições das associações à democracia, o trabalho pretende analisar as práticas de representação, em especial, a representação conselhista, como mais um repertório de ação que amplia e, em muitos casos, sobrecarrega suas ações, impactando potenciais benefícios democráticos. Trata-se de um exercício analítico em torno das seguintes questões: tendo em vista 1. as diferenças de perfil no campo associativo; 2. as características e requisitos desses formatos de representação institucional e 3. a participação das associações e movimentos sociais em diferentes frentes políticas e sociais, em que medida essa atuação institucional combina, ou atrita, com modalidades 
de ação mais participativas? É possível apontar para uma tipologia que reúna um conjunto de associações que melhor desempenhem essa função de representação institucional?

Palavras-chave: associações, participação, representação, conselhos, democracia.

Recebido: 29/07/2011 Aprovado: 05/09/2011

\section{ASSOCIATIONS, PARTICIPATION AND REPRESENTATION: COMBINATIONS AND TENSIONS}

By looking jointly at the debate on alternative forms of political representation and studies on associations and their contributions to democracy, this paper proposes to analyze the practices of representation, in particular the Brazilian councils, as another repertoire of action that expands and, in many cases, overloads associative action, impacting their democratic benefits. The paper proposes an analytical exercise based on the following questions. Keeping in mind the different profiles within the associative field, the characteristics and requisites of this kind of institutional representation, and the participation of associations and social movements in different political and social fronts, to what extent does this form of institutional action combine with or clash with more participatory forms of action? Is it possible to pinpoint a typology that would unite the group of associations that best perform the function of institutional representation?

Keywords: associations, participation, representation, councils, democracy. 


\section{ASSOCIAÇÕES, PARTICIPAÇÃO E REPRESENTAÇÃO: COMBINAÇÕES E TENSÕES*}

Lígia Helena Hahn Lüchmann

É fato que associações e movimentos sociais ${ }^{1}$ estão, além da atuação em suas respectivas frentes de trabalho, e sob diferentes objetivos, recursos e orientações, exercendo papéis de representação política em diferentes espaços institucionais de definição e de controle de políticas públicas, como são os casos, no Brasil, dos Conselhos Gestores nas diferentes áreas e setores de políticas governamentais, a exemplo

\footnotetext{
* Este trabalho faz parte do projeto de pesquisa (Bolsa PQ-CNPq) intitulado "Associativismo civil, participação e democracia: novas práticas e configurações". Agradeço a leitura e comentários de Mark Warren, Luciana Tatagiba e Adrian Gurza Lavalle, embora não tenha sido possível, aqui, incorporar várias das questões e sugestões.

1 De maneira geral, associações são grupos e organizações mais ou menos estruturadas ou hierarquizadas. Assim, além daquelas com autonomia organizacional, voluntárias e com relações internas mais igualitárias e menos hierárquicas, há também todo um conjunto de associações mais estruturadas, como sindicatos e associações profissionais. Embora também sejam, ou possam ser, associações, os movimentos sociais têm sido conceituados como articulação ou redes estabelecidas por grupos, coletivos e indivíduos que compartilham identidades e lutam por alguma causa. De acordo com Diani (1992, p.1), "movimentos sociais são definidos como redes de interações informais entre uma pluralidade de indivíduos, grupos e / ou organizações, engajados em conflitos políticos ou culturais e com base em identidades coletivas compartilhadas".
} 
da saúde, educação, assistência social, meio ambiente, transporte e planejamento urbano, entre muitas outras. Diferente de outros espaços e políticas participativas, na maioria desses Conselhos a participação institucional ocorre sob prerrogativas legais que determinam a representação por meio de associações, organizações ou "entidades sociais", fundamentalmente daquelas que atuam ou que contam com algum reconhecimento nas respectivas áreas de intervenção governamental.

Fruto de intenso debate, reivindicação e atuação de diferentes atores políticos e sociais, ${ }^{2}$ a institucionalização desses espaços amplia e complexifica o rol de modalidades, ou repertórios, de ação política das associações e dos movimentos sociais.

De acordo com Warren (2001), há certo consenso na literatura que aponta a importância das associações para a ampliação e o aprofundamento da democracia, na compre142 ensão de que - além do direito individual tendo em vista a satisfação de interesses - o associativismo preencheria, de forma substantiva, uma boa listagem de requisitos considerados fundamentais para o estabelecimento de uma sociedade democrática, seja pela sua capacidade de defen-

2 De acordo com Abers e Keck (2008, pp.102-103), "A ideia de conselhos gestores se originou com o movimento de Saúde, um dos poucos movimentos populares que continuou avançando durante os anos 1980. Ana Maria Doimo [...] atribui esse avanço ao fato de que, além da sua oposição ao regime militar, esse movimento tinha um programa concreto para novas instituições democráticas. $\mathrm{O}$ movimento propôs a descentralização do sistema de saúde, organizado em torno de prevenção e saúde pública, ao invés do investimento privado [...]. Um aspecto fundamental da proposta foi a institucionalização de conselhos nos níveis municipal, estadual e nacional, o que possibilitava a participação da população na tomada de decisões sobre as políticas de saúde. Para assegurar que os representantes do Estado não dominassem tais conselhos, a garantia de 'paridade' foi inserida na lei: representantes do Estado e grupos cívicos dividiriam o poder nos conselhos [...]. A legitimidade, tanto de tradicionais organizações de bairro como de novas ONGs profissionais, derivava da sua presumida ligação com movimentos de base". As outras áreas também testemunharam um intenso ativismo pela implementação dos respectivos conselhos. 
der as demandas dos grupos mais vulneráveis e excluídos; seja pelo caráter pedagógico no sentido da promoção de processos de educação política (de confiança, cooperação e espírito público); por denunciar as relações de poder, ou ainda por promover e ocupar os espaços de cogestão de políticas públicas, enriquecendo as bases da participação e da representação política nas democracias contemporâneas (Fung, 2003; Cohen, 1999; Putnam, 1996; Fung e Wright, 2001; Cohen e Rogers, 1995; Hirst, 1994; Warren, 2001; Chambers e Kopstein, 2006).

Essa "sobrecarga democrática" dada às associações vem sendo objeto de vários questionamentos. Warren (2001), entre outros ${ }^{3}$, procura analisar e especificar, no interior desse campo complexo e plural, os diferentes tipos de associações e seus diferentes, e muitas vezes contraditórios, efeitos democráticos. Desagregar e diferenciar as associações implica o reconhecimento de que muitas associações não são boas para a democracia, como determinados grupos privados, grupos racistas, de ódio, e muitos grupos de interesses poderosos que fazem jus às suspeitas de facciosismo levantadas por Madison e Rousseau em suas preocupações com o ideal do bem comum (Warren, 2001, p. 10). Além disso - e este é o ponto central de sua proposta de construção de uma teoria das associações no interior da teoria democrática -, é necessário distinguir as diferentes contribuições democráticas das associações, por meio de combinações mais ou menos efetivas que desenham um quadro plural denominado metaforicamente de "ecologia democrática das associações" (Warren, 2001, p.12), na medida em que as associações desempenham, de acordo com as suas características, diferentes atividades e funções, o que implica considerar que não se pode esperar que promovam, ao mesmo tempo, a defesa das demandas dos grupos mais

\footnotetext{
3 Para outros exemplos dessa análise, ver Paxton (2002); Stolle e Rochon (1998); Baggetta (2009); Robteutscher (2005); Fung (2003).
} 
vulneráveis e excluídos, o cultivo de habilidades cívicas e de educação política, a atuação como contrapesos de poder, a participação em espaços de governança, e ainda, a formação de opinião pública, para mantermos os exemplos apontados anteriormente. Para Warren, o problema de generalizar é o de apontar efeitos democráticos onde eles não existem (Warren, 2001, p.27) ${ }^{4}$.

O que se percebe é que, em muitos casos, associações e movimentos sociais que preenchem outros - e importantes - benefícios democráticos, assumem, para além de práticas de participação e de representação de base não eleitoral (Saward, 2006) ou informal, esses novos papéis de representação política institucional, precipitando novos desafios, tensões e sobrecargas que impactam, por um lado, na capacidade de promover representação democrática no campo institucional, e, por outro, na própria dinâmica da participação de associações e movimentos sociais. Um dos pontos 144 centrais dos debates sobre a pluralização da representação está localizado no reconhecimento de que representação e participação se complementam, superando abordagens que situam esses fenômenos de forma contraposta (Gurza Lavalle, Houtzager e Castello, 2006b; Lüchmann, 2007; Isunza Vera e Gurza Lavalle, 2010; Young, 2006; Castiglioni e Warren, 2006; Urbinati e Warren, 2008). Entretanto, as relações entre participação coletiva e representação institucional ocorrem, de acordo com cada contexto, não somente por meio de boas combinações, como também de tensões.

Com efeito, a ampliação e a pluralização nos repertórios de ação associativa, colocam, no horizonte das análises

\footnotetext{
4 Por exemplo, associações de advocacy podem ser boas para representar algumas causas e pessoas, mas não para promover alternativas de governança. Da mesma forma, clubes e associações de ajuda mútua podem exercer importante função integradora, mas estão longe de cumprirem com objetivos de contestação política (Warren, 2001). Assim, como veremos adiante, uma sobrecarga de atividades e funções pode implicar em perda, e não em acúmulo democrático.
} 
do associativismo e dos movimentos sociais, a necessidade de construir novos aportes analíticos que incorporem o fenômeno da representação política nas suas relações com as práticas de participação. Afinal, estamos falando de uma atuação política - a representação conselhista - que, diferente de promoção de campanhas, organização de protestos, representação de interesses de grupos, comunidades, identidades, promoção de atividades sociais e defesa de comunidades locais ou territoriais, colocam, na agenda desses atores coletivos, uma nova responsabilidade marcada pela dimensão da representatividade perante outros atores e com o Estado na formulação de políticas públicas que afetarão públicos mais amplos.

Diante disso, e conjugando o debate sobre formas alternativas de representação política e estudos que analisam os impactos ou contribuições das associações à democracia, este trabalho pretende analisar as novas práticas de representação política sustentadas por associações, com especial referência à representação conselhista, ou seja, aquela empreendida junto aos Conselhos Gestores de Políticas Públicas, como uma modalidade - ou repertório - de ação que amplia, e em muitos casos, sobrecarrega e tensiona os alegados benefícios democráticos das associações. Mais especificamente, pretende desenvolver um exercício analítico em torno das seguintes questões: tendo em vista 1. as diferenças de perfil no campo associativo; 2. as características e requisitos desses formatos de representação institucional; e 3. a participação das associações e movimentos sociais em diferentes frentes políticas e sociais, em que medida, em se constituindo em mais um repertório de ação política, essa atuação institucional combina, ou atrita, com modalidades de ação mais participativas? Tendo em conta a pluralidade associativa e os pressupostos básicos da representação democrática, é possível apontar para uma tipologia que reúna um conjunto de associações que melhor desempenhem essa função de representação institucional? 
Procurando empreender essa tarefa, o artigo está dividido em três partes. Na primeira, mobiliza a ideia de repertório (Tilly, 2006) procurando ressaltar que essas práticas de representação política fazem parte de um conjunto mais amplo de ações e estratégias políticas das associações e movimentos sociais. Na segunda parte, o artigo procura justificar o enquadramento dessas práticas de representação conselhista no debate contemporâneo sobre a "pluralização da representação" (Gurza Lavalle, Houtzager e Castello 2006b; Lüchmann, 2007), identificando, por meio de uma tipologia da representação política alternativa ao modelo eleitoral, as especificidades dessa representação associativa frente aos outros tipos ressaltados na literatura. Algumas tensões e impactos das relações entre participação e representação são apresentadas na terceira e última parte do artigo, fazendo uso de alguns exemplos empíricos emprestados da literatura.

\section{Representação institucional como novo repertório de ação política das associações}

Associações e movimentos sociais atuam com foco para diferentes objetivos e sob diferentes contextos, recursos e condições. Desempenham atividades de representação da população de onde estão inseridas, como no caso das associações comunitárias e/ou de moradores; ou em causas e temas que recobrem setores e espectros mais amplos, como as associações feministas, de negros, ambientalistas etc.; defendem os interesses dos seus associados, como clubes e sindicatos; e, ainda, atendem e representam as pessoas carentes e excluídas, como as entidades assistenciais e filantrópicas, para darmos apenas alguns exemplos. Gurza Lavalle, Houtzager e Castello (2006a), em pesquisa junto às associações de São Paulo, apresentam os principais argumentos ${ }^{5}$ que dão base

\footnotetext{
5 Quais sejam: o argumento eleitoral, o de afiliação, o de identidade, o de prestação de serviços, o de proximidade, e, finalmente, o argumento da intermediação. Os quatro últimos estão diretamente relacionados com a ideia de autoautorização.
} 
às reivindicações de representatividade por parte das associações, sendo que, em vários casos, predomina a ideia de autoautorização, na medida em que não ocorre nenhum tipo de procedimento de escolha e de controle por parte dos segmentos supostamente representados.

Diferentes, embora intimamente articulados com esses sentidos mais ou menos difusos e informais, são os novos formatos de representação oportunizados pela constituição de conselhos gestores, comitês, conferências e orçamentos participativos, na conformação de um cenário de pluralização e de complexificação dos espaços e repertórios, mais ou menos combinados, de participação e de representação (Lüchmann, 2007).

A representação institucional tornou-se mais uma modalidade de atuação política que foi incorporada, ou rotinizada, por um expressivo conjunto de associações e movimentos sociais $^{6}$. Nessa perspectiva, podemos dizer que essas práticas de representação se tornaram mais um repertório de ação política coletiva. Referência central na formulação do conceito de repertório, Tilly (2006) adverte que os repertórios de ação política, e, analisando mais especificamente, a ação contestatória, são performances que apresentam certa historicidade, ou seja, embora variem no lugar e no tempo, ocorrem a partir de modelos ou práticas preexistentes. Diferente de práticas localizadas ou esporádicas, os repertórios constituem um limitado número de performances que são reconhecíveis (Tilly, 2006, p.43). Por outro lado, estes também não são a reprodução de um hábito mudo, na medida em que a adoção de um repertório prévio ocorre com inovações. Uma determinada performance se transforma em repertório quando há conexões entre os demandantes e as organizações sociais existentes; há uma acumulação de experiências com

\footnotetext{
${ }^{6}$ Certamente, não todos, pois há um bom número de grupos, associações e movimentos que questionam o caráter institucional e acusam as dimensões instrumentais destas práticas, adotando posturas mais ativistas e/ou anti-institucionais.
} 
a performance, e determinado tipo de intervenção do regime. (Tilly, 2006, p.42). Repertórios estão assentados em identidades, laços sociais e formas organizacionais que constituem a vida diária, ou seja, na cultura, e variam de acordo com as condições e contextos políticos e sociais (Tilly, 2006). Uma dimensão central da ideia de contexto é revelada pela noção de "estruturas de oportunidades políticas"7 enquanto elementos centrais para entendermos os diferentes repertórios das ações de coletividades e de movimentos sociais. Com efeito, além da dimensão relacionada com legados históricos, aprendizados e recorrências, a ideia de repertório está vinculada a uma concepção que vê relações e complementariedades, e não apenas conflitos, entre as práticas associativas e movimentalistas e os atores e os espaços da política institucional (governos, partidos, parlamentos etc.).

A noção de repertório permite perceber variadas escolhas e práticas políticas não apenas entre diferentes asso148 ciações ou organizações, mas no interior das mesmas, que mobilizam diferentes estratégias de ação política e social de acordo com as suas demandas, os espaços institucionais disponíveis e os seus objetivos. Piquetes, marchas, demonstrações, ocupações, bloqueios, abaixo assinados, panfletagem, reuniões públicas, cartas, declarações na imprensa, lobbies, criação de associações, figuram entre os mais conhecidos repertórios de ação dos movimentos sociais (Tilly, 2006, p. 53). A modalidade escolhida, se mais contestadora e/ou mais institucional, depende de cada situação e das avaliações de participantes e ativistas sociais. As diferentes condições ou situações jogam papel decisivo nas estratégias adotadas, e que sofrem alterações à medida que essas condições, capacidades e restrições se desenvolvem. Assim,

\footnotetext{
7 Os principais elementos que conformam as estruturas de oportunidades políticas são: "as organizações formais de governo e de políticas públicas; a facilitação e a repressão das reivindicações dos grupos desafiantes por parte das autoridades e a presença de aliados potenciais, rivais ou inimigos" (McAdam; Tarrow; Tilly, 2009, p.26).
} 
os mesmos grupos que agem nas ruas e montam barricadas podem ser encontrados em grupos de pressão, escritórios de jornais e em partidos políticos [...]. Esses vários tipos de atividades podem ser combinados no repertório dos mesmos grupos e podem até ser empregados simultaneamente (McAdam, Tarrow e Tilly, 2009, p.33).

Da mesma forma, para Diani e Bison (2010, p. 227), "tanto a dinâmica conflituosa como a consensual podem ser encontradas no interior dos mesmos fenômenos gerais". Para Diani (1992, p. 15), a escolha do repertório depende de vários fatores, incluindo-se as oportunidades externas, considerações de natureza tática e/ou ideológica, e as ligações com outros atores no movimento.

Embora voltada para a análise de movimentos ou ações coletivas de caráter contencioso, essa noção de repertório parece útil também para pensarmos as práticas de representação institucional levadas a cabo por uma variedade mais ampla de associações, extrapolando, portanto, o campo dos movimentos sociais ${ }^{8}$. Além destes, testemunha-se a maciça presença de associações comunitárias, ONGs, entidades filantrópicas e/ou de base religiosa e fundações como exemplos de associações que ocupam e exercem esses espaços de representação. No entanto, diferente de se constituírem

8 De acordo com Diani (1992), os movimentos sociais são fenômenos diferentes de organizações ou associações, na medida em que se caracterizam como redes informais compostas por uma pluralidade de atores (individuais e coletivos) que compartilham identidades e atuam com orientação para o conflito. Na combinação dessas três características está assentada, no plano analítico, a especificidade dos movimentos sociais frente a outros tipos de ação ou organização coletiva. Associações e/ou organizações são centrais e podem ser consideradas um dos principais recursos da ação movimentalista, embora não se confunda com a mesma, na medida em que as associações formam uma importante base daquilo que a literatura dos movimentos sociais conceitua como estruturas mobilizadoras (McAdam, McCarthy e Zald, 2008). 
na razão de ser desse tipo de associativismo ${ }^{9}$, essa atuação representativa apresenta-se como uma nova frente de atuação política, e que se combina, de forma mais ou menos problemática, com as outras atividades políticas e sociais.

\section{Representação conselhista como um tipo de representação democrática}

Diferentemente de outras modalidades de representação política, a representação nos Conselhos Gestores ocorre por meio de associações, ou organizações sociais, que dividem esse papel com atores estatais. A despeito de suas especificidades institucionais, essa modalidade representativa parece se enquadrar bem no conjunto mais amplo de exemplos de experiências alternativas de representação política, na medida em que se constituem como espaços deliberativos que são preenchidos por cidadãos que têm a atribuição de representar outros cidadãos na formulação de políticas públicas 150 (Gurza Lavalle, Houtzager e Castello, 2006a; Gurza Lavalle, Houtzager e Castello, 2006b; Abers e Keck, 2008; Almeida, 2010; Lüchmann, 2007; Borba e Lüchmann, 2010; Isunza Vera e Gurza Lavalle, 2010). Olhar pela chave da representação pretende revelar em que medida essas práticas promovem a inclusão dos interesses e demandas dos grupos e setores sociais cujas vozes não alcançam expressão e reconhecimento nos espaços de representação política eleitoral. Pretende, portanto, avaliar em que medida esses espaços estão cumprindo o ideal democrático de ampliação de canais de acesso político, ou se, ao contrário, acabam exacerbando déficits de representação por meio de processos que privilegiam os grupos e setores com maiores recursos e mais organizados, ou seja, promovendo sobrerrepresentação (Cohen e Rogers, 1995; Warren, 2008; Castiglioni e Warren, 2006).

\footnotetext{
9 Como é o caso dos partidos políticos, organizados tendo em vista ocupar os espaços institucionais e governamentais de representação política.
} 
Além disso, desafia a se pensar em que medida essa atuação representativa, enquanto um novo repertório de ação política, impacta o próprio campo das práticas participativas de associações e movimentos sociais.

O princípio da inclusão política constitui o eixo central das análises que procuram teorizar sobre a dimensão democrática desses tipos alternativos de representação. Como sabemos, o modelo da representação eleitoral é aquele no qual os representantes são autorizados, por meio de eleições, a representarem os cidadãos, agindo em nome de seus interesses e prestando contas nas eleições subsequentes (Urbinati e Warren, 2008). Em que pesem todos os avanços democráticos no sentido da universalização e da equalização legal, esse modelo, baseado nos partidos e no sufrágio universal, apresenta déficits democráticos dados, entre outros $^{10}$, pela dispersão, pluralização e complexificação das demandas e dos interesses sociais que transcendem os limites territoriais do modelo padrão eleitoral (Saward, 2009). De acordo com Urbinati e Warren (2008, p. 389), um dos mais importantes desafios para se pensar a representação política é o deslocamento, a pluralização e a redefinição do que constitui o campo dos representados, ou dos constituintes, tradicionalmente definidos pelo seu vínculo territorial, o que exclui outras dimensões e questões da vida política e social, como as dimensões de gênero, religiosas, étnicas, migratórias, ambientalistas, entre outras.

Diante disso, promover representação democrática implica ampliar os espaços e os atores, não no sentido da substituição, mas da complementação e da qualificação da

\footnotetext{
${ }^{10}$ São vários os argumentos que apontam as distâncias entre representantes e seus representados, a começar pela própria incapacidade de identificar os interesses e demandas destes últimos, seja pela pluralidade de indivíduos, seja pela volatilidade de suas preferências, ou ainda pelas desigualdades socioeconômicas. De acordo com Saward (2009, pp. 3-4), "nenhum de nós é totalmente representado - a representação de nossos interesses ou identidades, na política, é sempre incompleta e parcial [...] a representação eletiva não esgota a representação democrática”.
} 
representação eleitoral, dialogando de forma direta com as perspectivas participativas e deliberativas da teoria democrática, na medida em que pretendem operacionalizar a legitimidade política ancorada na ideia de que as decisões políticas devem ser tomadas de modo a garantir oportunidades para que os indivíduos e grupos afetados possam influenciar essas decisões (Young, 2006; Castiglioni e Warren, 2006) ${ }^{11}$.

Na literatura, são muitos os exemplos de representação alternativa ou de práticas de representação política exercidas por indivíduos e grupos, e que operam sob pressupostos diferentes do modelo eleitoral. Pessoas, grupos ou associações reivindicam representar outras pessoas, grupos, populações, os animais e a natureza, independente de terem sido formalmente escolhidos pelos supostos representados, ou de terem sido autorizados por processos alternativos ao modelo padrão do sufrágio universal. Os exemplos oscilam entre experiências de representação formais ou informais; 152 coletivas ou individuais. Como exemplo de representação formal de base individual, podemos considerar a Assembleia de Cidadãos da Colúmbia Britânica (Warren e Pearse, 2008) ${ }^{12}$, audiências públicas, conselhos consultivos, júris de cidadãos e as Pesquisas de Opinião Deliberativas ${ }^{13}$. No caso

${ }^{11}$ De acordo com Castiglioni e Warren, "O grau no qual uma relação representativa é 'democrática' irá depender do grau em que ela permite a seguinte norma: cada indivíduo potencialmente afetado por uma decisão deve ter a mesma oportunidade para influenciar a decisão. A norma de ação corolária é aquela na qual as ações coletivas devem refletir as propostas decididas sob processos inclusivos. Em resumo, a norma básica da democracia é a inclusão empoderada daqueles que são afetados pelas decisões e ações coletivas (2006, p.4; grifos dos autores).

12 A Assembleia dos Cidadãos da Colúmbia Britânica foi uma inovação proposta pelo Governo Provincial que, seguindo uma promessa de campanha eleitoral, instituiu um corpo deliberativo formado por 160 cidadãos que se reuniram durante 11 meses em 2004 para avaliar o sistema eleitoral e recomendar um novo sistema, em caso de avaliarem a necessidade de mudança. $\mathrm{O}$ resultado desse processo, que contou com várias rodadas de discussão e encontros, foi submetido a um referendum, cujo resultado $-57,7 \%$ de aprovação - não logrou os $60 \%$ necessários para a sua implementação. Vários estudos sobre esse processo estão reunidos em Warren e Pearse (2008).

${ }^{13}$ Coordenadas por Fishkin e colaboradores. Para uma análise deliberativa desses experimentos, ver Fishkin (2010). 
de representação coletiva e informal, temos os exemplos da atuação de ONGs e movimentos sociais em diferentes esferas públicas em níveis locais, nacionais e internacionais. Encontramos ainda citações e análises de práticas de representação individual e informal, como o já conhecido caso do discurso de Bono, cantor do U2 (Dryzek e Niemeyer, 2008; Saward, 2009) ${ }^{14}$. A representação das associações junto aos Conselhos Gestores ${ }^{15}$ no Brasil figura como exemplo de representação coletiva e formal, preenchendo, portanto, um quadro formado por quatro modalidades de práticas alternativas de representação. Assim, podemos sistematizar uma espécie de tipologia das representações alternativas ao modelo eleitoral, qual seja: 1. informal e individual; 2. informal e coletiva; 3. formal e individual; e 4. formal e coleti$v a^{16}$. A formalidade diz respeito à existência de regras institucionais, seja de caráter legal ou não, e geralmente conta com a participação governamental, como são os casos dos

${ }^{14}$ Saward (2009, p. 1) abre o seu artigo com este exemplo: "Em meio à campanha 'Make Poverty History', em 2004, o vocalista do U2 e ativista político Bono disse: 'eu represento um grande número de pessoas [na África] que absolutamente não têm voz [. . . Eles não me pediram para representá-los. É atrevido, mas eu espero que eles fiquem contentes por eu fazer isso"”.

${ }_{15}$ Os Conselhos Gestores de Políticas Públicas são amparados por legislação nacional e que apresentam um caráter de política pública mais estruturado e sistêmico, sendo previstos atuarem nas três esferas governamentais (municipal, estatal e nacional). Apresentam atribuições legais de formulação, acompanhamento e fiscalização das políticas nas respectivas esferas governamentais, se constituindo como instituições públicas de referência para a captação e formulação de demandas dos diversos grupos sociais por meio da representação dos diferentes setores e segmentos, fundamentalmente aqueles com menos acesso aos recursos e bens econômicos, políticos e sociais. Duas características centrais desses espaços são: a representação de entidades ou organizações da sociedade civil e a paridade na representação entre sociedade civil e Estado. Há diferentes composições de paridade. No caso da área da saúde, a paridade ocorre entre a representação dos usuários e os demais representantes ou setores: Estado, prestadores de serviço e trabalhadores da área.

${ }^{16}$ Há certamente combinações entre esses diferentes tipos, como são os vários exemplos de orçamento participativo que combinam os tipos 3 e 4 . Além disso, parece possível supor graus variados de representatividade, na construção de uma escala na qual os tipos 1 e 2 ocupariam posições de representatividade mais fraca. Montanaro (2009) faz um interessante estudo nesta direção. 
Conselhos no Brasil e da experiência da Colúmbia Britânica no Canadá.

Tipologia das práticas alternativas de representação política

\begin{tabular}{|c|c|c|c|}
\hline Tipo 1 & Tipo 2 & Tipo 3 & Tipo 4 \\
\hline $\begin{array}{c}\text { Informal e } \\
\text { individual }\end{array}$ & $\begin{array}{c}\text { Informal e } \\
\text { coletiva }\end{array}$ & $\begin{array}{c}\text { Formal e } \\
\text { individual }\end{array}$ & $\begin{array}{c}\text { Formal e } \\
\text { coletiva }\end{array}$ \\
\hline $\begin{array}{c}\text { Atuações e } \\
\text { manifestações } \\
\text { públicas de } \\
\text { indivíduos que } \\
\text { reclamam a } \\
\text { representação } \\
\text { sem autorização } \\
\text { para tal }\end{array}$ & $\begin{array}{c}\text { Atuações e } \\
\text { manifestações } \\
\text { públicas de } \\
\text { associações } \\
\text { que reclamam } \\
\text { a representação } \\
\text { sem autorização } \\
\text { para tal }\end{array}$ & $\begin{array}{c}\text { Atuações e } \\
\text { manifestações } \\
\text { públicas de } \\
\text { indivíduos que } \\
\text { foram autorizados } \\
\text { e selecionados, de } \\
\text { diferentes formas, } \\
\text { para o exercício da } \\
\text { representação }\end{array}$ & $\begin{array}{c}\text { Atuaçes e } \\
\text { manifestações } \\
\text { públicas de } \\
\text { associações que } \\
\text { foram autorizadas } \\
\text { e selecionadas, de } \\
\text { diferentes formas, } \\
\text { para o exercício da } \\
\text { representação }\end{array}$ \\
\hline
\end{tabular}

Revelando um horizonte mais rico no fenômeno da representação política, essas experiências e instituições vêm suscitando um debate que procura alargar a concepção de representação que está baseada nos requisitos da autorização e da accountability operacionalizados pelas instituições democráticas de base eleitoral. De acordo com Pitkin (1972), diferente de outras práticas ou atividades representativas, a representação política implica em tornar de alguma forma presente os que estão ausentes, agindo no interesse (Acting for) dos representados de forma responsiva a eles, o que requer a adoção de mecanismos de autorização e accountability. Tendo em vista a ausência, em muitos casos, ou a pluralidade, em vários outros, desses requisitos nas práticas alternativas, o desafio teórico passa a ser o de tentar encontrar outros equivalentes ou critérios que possam validar a dimensão democrática dessas experiências (Castiglioni e Warren, 2006; Rehfeld, 2006; Isunza Vera e Gurza Lavalle, 2010).

São várias as propostas analíticas para esse quadro plural e diferenciado de práticas representativas. Gurza Lavalle, 
Houtzager e Castello (2006a) denominam de "representação presuntiva"17 ou "virtual" às práticas de representação alternativas que não envolvem mecanismos de autorização, com especial ênfase àquelas desempenhadas pelas organizações da sociedade civil. Resgatando a dimensão subjetiva da representação, os autores buscam inspiração nas ideias de Burke para pensar a representação como o "sentimento" ou o "compromisso" para com o representado. (Gurza Lavalle, Houtzager e Castello, 2006b). Dryzek e Niemeyer (2008) apresentam a proposta de "representação discursiva" como a melhor saída frente aos problemas colocados pela complexidade e pluralidade social. Sabendo que os indivíduos como um todo não podem ser representados, seja pelo modelo da democracia representativa, limitado em face de um mundo marcado por subjetividades multifacetadas e formado por diferentes espaços e relações que atravessam fronteiras locais, nacionais e internacionais; seja pela impossibilidade de incorporação direta dos cidadãos em procedimentos deliberativos, em função dos problemas de escala, a representação por meio de discursos ${ }^{18}$ permitiria, de acordo com os autores, abarcar a diversidade de demandas, propostas e projetos, e impedir que os espaços de discussão política sejam dominados por um único discurso, aceito acriticamente pelos seus participantes. A inclusão de outros e contrapostos discursos constitui-se, portanto, em garantia de inclusão. Entretanto, como os próprios autores assinalam, essa representação discursiva é mais apropriada para as situações nas quais há dificuldades

\footnotetext{
17 "A presunção pública de representar alguém não equivale à sua efetiva representação, mesmo se amparada empiricamente pelo desempenho de atividades que, em princípio, pressuporiam o exercício de alguma modalidade de representação política. Contudo, o comprometimento com os interesses representados é um componente vital da representação, irredutível a dispositivos institucionais". (Gurza Lavalle, Houtzager e Castello, 2006a, p. 47).

${ }^{18}$ Discurso entendido como "Um conjunto de categorias e conceitos que envolvem determinados pressupostos, julgamentos, disposições, disputas e capacidades" (Dryzek e Niemeyer, 2008, p. 481). Os discursos relevantes são aqueles que apresentam concepções mais amplas e que, portanto, podem ser identificados.
} 
de se localizar ou precisar os representados, especialmente nos casos que envolvem contextos internacionais ${ }^{19}$.

Saward (2009) também procura justificar a legitimidade democrática de um amplo e diversificado conjunto de práticas alternativas de representação, ou de representação não eleitoral. Analisando as "reivindicações de representação" (representative claims), o autor evoca para a necessidade de uma revisão radical do que seja o representado, podendo ser indivíduos, grupos, populações extraterritoriais, animais, a natureza. De acordo com o autor, os limites da representação eleitoral podem ser contornados pelas diferentes expressões de representação não eleitoral, e que permitem, por exemplo, a promoção de processos contínuos de representação sem as tentações dadas pelos momentos eleitorais, ou de processos temporários voltados à resolução de problemas específicos, ou ainda a criação de espaços e agendas que transcendem critérios territoriais, formando um quadro mais fluido de práticas de representação política 156 (Saward, 2009, p.8-9). Sejam baseadas em vínculos identitários, na tradição, na posse de conhecimento especializado, na vocalização de grupos e populações pauperizadas e discriminadas, nas demonstrações públicas e massivas de suporte popular, nos argumentos de similaridades (descritivos), as reivindicações de representação descansam em uma variedade de justificativas outras do que a justificativa dada pelo processo de autorização eleitoral. O reconhecimento do público alvo constitui-se, nesta perspectiva, na base de legitimidade da representação uma vez que os agentes que reivindicam a representação podem apresentar propostas inaceitáveis ou sem qualquer conexão ou ressonância social (Saward, 2006). Além disso, a questão cen-

19 De acordo com os autores, "Nós não reivindicamos que a representação dos discursos seja sempre preferível à dos indivíduos, mas apenas que é diferente; às vezes mais factível quando a representação das pessoas não é tão possível (especialmente em contextos transnacionais nos quais há ausência de um demos bem definido) sendo que, sob determinados critérios e situações, pode fazer melhor" (Dryzek e Niemeyer, 2008, p. 481). 
tral da ideia de "reivindicação da representação" está no reconhecimento de que o que é representado é uma construção, e não algo dado ou predefinido, o que aponta para o seu caráter dinâmico e criativo (Abers e Keck, 2008) que, envolvido em disputas de significados, permite que uma audiência potencial tenha autoconsciência de si como audiência real podendo, portanto, contestar essa representação (Saward, 2006, p. 303). A essa dimensão estética, e, portanto, criativa, da representação, o autor adiciona a dimensão cultural, dada pelo contexto dos códigos compartilhados. Assim, longe de um processo criativo que opera no vazio, os significados atribuídos pelos reclamantes da representação precisam estar referidos aos respectivos contextos, sendo reconhecidos, interpretados, ou resignificados pelas suas audiências ou representados (Saward, 2006, p. 312).

À parte os questionamentos acerca da ampliação e flexibilização do sentido de representação, o fato é que, diferente dos tipos informais, a representação conselhista está ancorada em aspectos institucionais e legais que normatizam um tipo de representação voltada para a formulação de políticas públicas, e que, portanto, afetam setores sociais mais amplos. Embora a existência de procedimentos institucionais de autorização, a diversidade e o escopo dos mesmos apontam as distâncias em referência ao procedimento eleitoral. Mesmo que com diferenças entre os campos de políticas, os Conselhos estão estruturados em regras que estabelecem, em função de sua trajetória de constituição, a representação por via das organizações da sociedade civil, vistas como portadoras legítimas dos interesses sociais ${ }^{20}$. Assim, as especificida-

\footnotetext{
${ }^{20}$ Como analisam Gurza Lavalle, Houtzager e Castello (2006a, p.46), a representação da sociedade civil está imbuída da ideia de que os seus atores "emergem em continuidade ou animados por uma conexão genuína com o tecido social - ou mundo da vida, como se queira. Essa continuidade pressuposta tende a dissipar a formulação de questões como em nome de quem e mediante quais mecanismos de controle e responsividade representam as organizações civis".
} 
des dadas pelos sujeitos representativos (atores coletivos), o caráter voluntário da representação, e a variedade de formas e procedimentos de escolha são, além de se constituírem em espaços político-institucionais, ou seja, constituídos no interior da institucionalidade estatal, elementos importantes que demarcam a necessidade de se avançar nas reflexões acerca da natureza democrática desse tipo de representação. Afinal, como analisam Borba e Lüchmann (2010), mesmo com essa natureza mais voluntária e plural, esses espaços conselhistas não eximem seus atores representativos da justificação de sua atuação, na medida em que se propõem a agir em nome de outros e a tomarem decisões que afetam públicos amplos. Assim como na experiência da Assembleia de Cidadãos da Colúmbia Britânica, criada pelo poder público para apresentar uma proposta de sistema eleitoral, os Conselhos são instituições criadas, cada qual, para discutir, formular, acompanhar e avaliar as ações e políticas estatais em cada setor 158 da política social. Diferentes, portanto, da pluralidade de práticas informais, são espaços "empoderados" (Castiglione e Warren, 2006), na medida em que se colocam como referência central - e com reconhecimento legal e político institucional de atuação política nas diferentes áreas das políticas públicas ${ }^{21}$. Implicam, portanto, que os representantes desempenhem funções, ou obrigações, que requerem tempo, compromisso e qualificação, além de algum mecanismo, ou equivalente, de responsividade ou justificação ${ }^{22}$.

A accountability diz respeito, portanto, aos processos ou mecanismos de justificação junto aos representados e que ocorre, nesses casos, de forma retrospectiva, adquirindo

\footnotetext{
${ }^{21}$ Embora façam parte de um sistema institucional mais amplo, e que envolve outros espaços mais empoderados, tanto no âmbito do Executivo como no Legislativo. ${ }^{22}$ E que preveja, portanto, algum tipo de presença dos representados, seja autorizando a representação e/ou cobrando respostas ou justificativas dos representantes. Os autores apontam diferentes possibilidades de responsividade, por meio de mecanismos variados como eleições, voz, saída, processos deliberativos, controle ou fiscalização, e confiança (Urbinati e Warren, 2008, p. 396).
} 
um caráter público e reflexivo (Castiglioni e Warren, 2006, p. 15-16). Constitui-se como processo que se desenvolve no tempo, e que, embora se desapegue de um ato de autorização inicial (Isunza Vera e Gurza Lavalle, 2010, p. 45), ocorre por meio de relações, ou conexões com os representados (Young, 2006), revelando as necessárias e importantes combinações entre participação e representação ${ }^{23}$. Entretanto, como veremos a seguir, e fazendo uso de alguns exemplos retirados de estudos empíricos, participação e representação também geram sobrecargas e tensões.

\section{Compatibilidades e tensões entre participação e representação}

Como vimos, a literatura aponta a representação como um dos benefícios democráticos das associações, salientando as relações positivas, e não contrapostas, entre participação e representação. Com um olhar analítico do campo associativo mais amplo, Warren (2001) apresenta de forma mais detalhada algumas características que abrigam três tipos de benefícios democráticos que são, potencialmente, produzidos pelas associações, quais sejam: desenvolvimento individual no sentido de, entre outros, prover julgamentos autônomos; efeitos nas esferas públicas tendo em vista a formação de opinião e de julgamentos públicos; e impactos político-institucionais, seja ampliando e qualificando a representação política, seja cooperando para formas alternativas de governança (Warren, 2001, p.60). A partir desse reconhecimento, o autor

23 Em trabalho anterior baseado em pesquisas empíricas (Borba e Lüchmann, 2010) mobilizamos duas variáveis para analisar a representatividade dos conselheiros. A primeira diz respeito ao desenho institucional dos Conselhos. A segunda é a configuração da sociedade civil, sugerindo que "o exercício da representação parece ser dinamizado à medida que o(a) conselheiro(a) está ligado(a) a organizações que tenham uma trajetória de atuação política na área e uma dinâmica interna mais participativa e mobilizadora. Já quando as organizações possuem uma identidade eminentemente corporativa, ou um foco de ação assistencialista, a tendência é uma fragilização no vínculo representativo. Os conselheiros, nesse caso, representam a eles mesmos, como foi explicitado em vários depoimentos" (Borba e Lüchmann, 2010, p. 244). 
se debruça para construir uma tipologia das associações, tendo em mente a sua maior ou menor potencialidade de promover tipos diferenciados de efeitos democráticos. A ideia é poder responder à pergunta: que tipos de associações provocam que tipos de efeitos democráticos (Warren, 2001, p.94)? Embora reconheça a interferência de outras variáveis, a exemplo da estrutura organizacional e do perfil da liderança, o autor identifica algumas características que considera centrais para a promoção - ou não - de diferentes benefícios democráticos. $\mathrm{O}$ fato de a associação estar ou não integrada (vested) ao meio social; o caráter da voluntariedade; os meios (relações sociais, poder ou dinheiro) constitutivos; e os objetivos das associações são elementos que permitem avaliar as suas diferentes práticas, escolhas e orientações (Warren, 2001) ${ }^{24}$.

Cohen e Rogers (1995) apresentam uma perspectiva democrática que potencializa o papel e a importância das 160 associações, dialogando com perspectivas liberais, republicanas e pluralistas que apontam críticas, sob diferentes graus e perspectivas, centradas nas ameaças advindas de uma maior aproximação das associações com o poder político. Na listagem de problemas apontados por estas frentes analíticas podemos encontrar os riscos de facciosismo, da balcanização de interesses no interior do estado, de seu domínio por determinados grupos da sociedade, e da ineficiência advinda do aumento das demandas sociais organizadas. Entretanto, embora reconheçam contribuições dessas diferentes vertentes, os autores advertem que todas

\footnotetext{
${ }^{24}$ Assim, por exemplo, associações integradas, voluntárias, sociais e com objetivos de socialização ou de integração social podem ser boas para promover civilidade ou confiança, mas estão longe de produzir efeitos democráticos na esfera da política institucional. De outra forma, associações integradas, econômicas, não voluntárias e com objetivos de defesa de interesses de setores dos trabalhadores, como os sindicatos, por exemplo, são boas para a promoção de maior igualdade social, mas apresentam maiores dificuldades de representação de diferenças na esfera pública (Warren, 2001).
} 
elas falham na visão da importância dos grupos e das associações, e na necessidade de avaliar as suas variações qualitativas e a sua artefactualidade enquanto elementos motivadores para se pensar positivamente os seus impactos para a democracia (Cohen e Rogers, 1995).

Para os autores, ao contrário de ameaças à democracia, as relações entre as associações e o Estado permitiriam a promoção do ideal do bem comum, configurando um processo de soma positiva por meio do aumento do poder das associações e da maior eficiência do estado e do mercado, o que significaria o fortalecimento da ordem democrática (Cohen e Rogers, 1995). Nessa perspectiva, os autores apontam pelo menos quatro funções que, por serem preenchidas pelas associações, justificam a importância da democracia associativa frente aos problemas e desafios colocados pela complexidade social. Por um lado, pelo fato de sua maior proximidade com os problemas e maior conhecimento da realidade em que estão inseridas, as associações são recursos imprescindíveis de produção e de oferta de informações, consideradas centrais para a qualificação e clarificação das deliberações e decisões políticas. As associações também preencheriam com os requisitos democráticos da equalização da representação política, ao proporcionarem oportunidades de explicitação de vozes e demandas aos indivíduos e setores com menos recursos e poder, e que tradicionalmente têm sido excluídos da representação política eleitoral de base territorial (Cohen e Rogers, 1995, p. 43). Além disso, e seguindo a tradição participacionista, as associações podem funcionar como "escolas de democracia", desenvolvendo virtudes cívicas, competências políticas e autoconfiança, e promovendo o valor básico do reconhecimento das normas democráticas. Por último, as associações são vistas como centrais para a conformação de uma governança alternativa. Aqui, para além de representarem interesses, as associações atuariam com funções "quase públicas" na suplementação de fornecimento de 
serviços públicos, promovendo, por meio da cooperação e da confiança, melhor performance econômica e aumento da eficiência estatal. Com efeito, para esses autores, a democracia associativa requer um papel ativo das associações, participando diretamente nos espaços e instituições voltadas para a formulação das políticas, a coordenação das atividades econômicas, e o revigoramento e a administração das políticas públicas (Cohen e Rogers, 1995, p. 55).

Duas dimensões são centrais nessa abordagem da democracia associativa e que justificam a elaboração de uma proposta democrática que prevê uma atuação mais ousada por parte do Estado na adoção de uma política para as associações, para além da necessidade de reforma das próprias instituições políticas. A primeira dimensão diz respeito ao caráter da artefactualidade. De acordo com Cohen e Rogers (1995, p. 46), diferente de serem fenômenos naturais, ou produtos da cultura ou de algum outro substrato inalterado 162 da vida social, as associações são artefatos. Dependem das estruturas econômicas e políticas, dos recursos e das instituições nas quais estão inseridas. Podem variar de acordo com a maior centralidade ou não de governos, de informações disponíveis, das oportunidades e dos incentivos. Mudam de acordo com as escolhas políticas. Isso significa que o Estado tem um papel ativo e importante não apenas na reforma institucional tendo em vista incorporar as associações nos processos de discussão, de formulação e de execução de políticas, como na própria formação das associações, provocando e incentivando de forma mais incisiva, agindo diretamente no meio ambiente associativo no sentido de evitar a formação de facções e estimular, por meio de taxas, subsídios e sanções legais, o desenvolvimento de associaçãos respeitosas das normas democráticas igualitárias.

A segunda dimensão aponta para o caráter qualitativo das associações. Tendo em vista enfrentar os argumentos que sustentam os riscos das facções, das diferenças de 
recursos e de poder no interior do campo asssociativo, essa dimensão procura delimitar determinadas características da vida associativa interna visando extrair os elementos que fazem diferença sob o ponto de vista do ideal democrático. Assim, partindo do pressuposto de que os grupos e as associações diferem em seus padrões de decisão interna, na sua maior ou menor capacidade de inclusão de membros, nas suas relações com outras associações, na natureza e extensão de seu poder, e no escopo de suas funções e responsabilidades ${ }^{25}$, os autores descartam uma visão que generaliza o campo das associações, apontando seletivamente para aquelas que preenchem as qualidades sugeridas pelo modelo, a exemplo de sindicatos e outras associações com representação mais ampla de setores sociais ${ }^{26}$. Pensando mais especificamente na atuação representativa das associações, podemos recuperar, na análise sugerida, algumas características tais como: liderança com poder e accountability junto aos membros; abrangência da associação no sentido de abarcar, como membros, a população afetada pela sua atuação; natureza pública dos objetivos e ações assumidas; elevado grau de informação e conhecimento, especialmente dados pelo seu vínculo com a população; e grau de interação com outros grupos, compartilhando informações, respeitando e colaborando com outros programas e atividades (Cohen e

${ }^{25}$ Os autores apresentam uma lista de sete traços que variam desde a accountability interna ao caráter de relações com o estado (Cohen e Rogers, 1995, p. 48-50).

${ }^{26}$ Essa seletividade é objeto de críticas, a exemplo de Young (1995) que, embora reconheça o mérito da proposta associativa, reclama da necessidade de inclusão dos grupos menos estruturados dos setores oprimidos e marginalizados. De acordo com a autora, há que se fazer distinções entre associações e grupos sociais, na medida em que uma associação é uma instituição formalmente organizada (como um clube, corporação, partido político, igreja ou sindicato) (Young, 1995, p. 210). Grupos sociais são menos artefactuais e mais "naturais" na sociedade. Embora sejam construídos socialmente e sejam mutáveis, não se constituem por meio de decisões explícitas ou por meio de políticas institucionais. Apresentam afinidades de experiências similares de tipo de vida e são também atores centrais para a política e a democracia, a exemplo dos grupos organizados pelo recorte de gênero, etnia, raça, religião e orientação sexual (Young, 1995, p.209). 
Rogers, 1995, pp.48-50). No que diz respeito à responsividade, e em se tratando de associações que atendem ao pressuposto da abrangência, os autores apontam vários mecanismos possíveis, como eleições, estruturas organizacionais internas, e promoção de encontros e debates (Cohen e Rogers, 1995, p.71).

Nessa perspectiva, nem todas as associações seriam boas para a representação conselhista de caráter institucional na medida em que esta representação requer, a princípio, e em se tratando de um exercício baseado na construção de uma tipologia que atenda aos pressupostos da representação democrática anteriormente apresentados, associações que: objetivem a representação política, ou que sejam reivindicantes desta - como vimos em Saward (2009) -, e que apresentem uma estrutura que atenda aos seus pressupostos, no sentido de garantir uma legitimidade dada por algum tipo de conexão e de responsividade. Além 164 disso, é necessário que as associações estejam voltadas para interesses públicos, sejam abertas ao diálogo com outros atores políticos e sociais, e tenham recursos (no mínimo de tempo, conhecimento e informação) para uma representação qualificada. E ainda, considerando, como vimos, que o público - ou o que é representado - não está dado $a$ priori, sendo uma construção, uma representação democrática requer mecanismos de ativação do representado, especialmente nas situações, a exemplo de vários Conselhos, em que os representados mais excluídos encontram-se, em muitos casos, desorganizados ${ }^{27}$.

Diante disso, o grau de exigência de uma atuação representativa democrática não apenas limita o quadro de associações que atendam a esses critérios, como coloca tensões na dinâmica das relações entre participação e

\footnotetext{
${ }^{27} \mathrm{O}$ que inviabiliza a possibilidade de accountability via confiança, na medida em que esta implica em algum tipo de vínculo ou informação acerca da atuação dos representantes (Castiglioni e Warren, 2006; Dahl, 1992).
} 
representação. Por um lado, temos as associações com mais recursos, porém com baixo grau de representatividade, o que configura o fenômeno da sobrerrepresentação. Por outro lado, as associações mais participativas e combativas que, embora alcancem maior grau de conexão com os setores marginalizados, sofrem os efeitos da representação institucional dados pela sobrecarga da dupla atuação nos campos da participação e da representação. Além disso, associações e movimentos sociais competem e conflitam entre si na busca de recursos e reconhecimento social. Associações inseridas no mesmo campo cooperam ou competem, de acordo com seus recursos, projetos e avaliações estratégicas para o alcance de seus objetivos. Em se tratando dos movimentos sociais, como analisa Melucci, estes constituem-se, fundamentalmente, pela via da articulação, ou seja, não são estruturas homogêneas e bem-definidas, ou personagens com identidades claras e fixas, mas sim "fenômenos heterogêneos e fragmentados que devem destinar muitos dos seus recursos para gerir a complexidade e a diferenciação que os constitui" (Melucci, 2001, p. 29). Com efeito, além da sobrecarga de repertórios e os conflitos nas suas escolhas, ressalta-se as tensões dadas pelos diferentes lócus (e respectivas características e exigências) da participação e da representação institucional.

Alguns exemplos são resgatados dos estudos empíricos para pensarmos nessas sobrecargas e tensões. O primeiro, resgatado do estudo de Tatagiba e Blikstad (2010), diz respeito à participação do movimento de moradia junto ao Conselho Municipal de Habitação (CMH) de São Paulo. Criado em 2002 pela pressão dos movimentos de moradia e de reforma urbana da cidade, o $\mathrm{CMH}$ constitui-se como espaço estratégico no campo das políticas habitacionais, sendo um "órgão deliberativo, fiscalizador e consultivo, que tem como objetivos básicos o estabelecimento, acompanhamento, controle e avaliação da política municipal de habi- 
tação" (Tatagiba e Blikstad, 2010) ${ }^{28}$. De acordo com as autoras, os movimentos sociais na área da habitação vêm disputando os espaços de representação no $\mathrm{CMH}$, sendo que o Movimento de Moradia (MOM) apresenta sérias dificuldades em conciliar uma agenda mais ampla de representação no conselho com as agendas, ou os interesses e demandas mais específicas, e diferenciadas, das organizações e dos grupos que compõem o movimento (Tatagiba e Blikstad, 2010, p.1132). À sobrecarga de atividades e funções, soma-se as tensões na escolha das estratégias e repertórios - se mais combativos ou institucionais - desencadeando diversos conflitos e rupturas, também influenciadas pelas relações com os setores político-institucionais (Tatagiba e Blikstad, 2010).

Um segundo exemplo é oferecido pelo estudo de Silva et al. (2010) sobre a representação social no Conselho Nacional de Saúde (CNS), criado em 1990. De caráter permanente e deliberativo, o CNS constitui-se como instância de formu166 lação e de controle das políticas de saúde no plano nacional, sendo composto por diferentes segmentos: usuários, trabalhadores, gestores e prestadores de serviço. O estudo assinala a forte presença e participação dos trabalhadores da saúde, por meio de uma representação organizada e articulada com o Fórum de Entidades Nacionais de Trabalhadores da Saúde, o que tem qualificado e fortalecido esse setor no interior daquele espaço conselhista. Seguindo esse modelo,

\footnotetext{
28 "O CMH é composto por 48 membros titulares e 48 suplentes. O poder público possui um terço dos assentos. Os outros dois terços são reservados aos conselheiros da sociedade civil, sendo 16 representantes de entidades comunitárias e de organizações populares ligadas à habitação; e 16 representantes de outras entidades da sociedade civil ligadas à questão habitacional, como ONGs, universidades, sindicatos etc. Os representantes do poder público são indicados pelos poderes executivos. Os representantes das entidades da sociedade civil são eleitos por seus respectivos segmentos em fóruns próprios. Já os representantes das entidades populares ligadas à habitação são escolhidos por meio de eleições diretas nas subprefeituras" (Tatagiba e Blikstad, 2010, p.1125-1126). Essa configuração se diferencia do modelo de representação que caracteriza a maioria dos conselhos no país, na medida em que coloca o ingrediente eleitoral individual, complexificando esse espaço ao aproximá-lo do modelo padrão eleitoral.
} 
o segmento dos usuários vem procurando maior articulação com o Fórum de Entidades de Portadores de Patologias e Deficiências, o que revela também o reconhecimento da importância da participação para qualificar, fortalecer e legitimar a representação. No entanto, como os autores apontam, diferente dos trabalhadores da saúde, o setor dos usuários (o mais abrangente e com menos recursos) apresenta muitos limites para uma articulação mais ampla e qualificada. Para esses setores, a representação ocorre em detrimento da participação, na medida em que a primeira absorve os escassos recursos existentes (Silva et al., 2010). Como resultante, testemunha-se assimetrias entre as organizações sociais representadas, configurando, como demonstrado em muitos outros estudos, o fenômeno da sobrerrepresentação.

Nesse caso, temos o exemplo que aponta os impactos negativos da representação sobre a participação dados, entre outros, pela sobrecarga de responsabilidades e de frentes de atuação. De fato, a pluralidade de espaços - mais ou menos institucionais ou formais - de participação e de representação no país desencadeou um processo de institucionalização das associações e dos movimentos sociais, cada vez mais sobrecarregados e tensionados pela adoção de diferentes repertórios de ação política. Conselhos, conferências, audiências públicas, assembleias, seminários, reuniões, fóruns, entre muitos outros, conformam um complexo participativo que superpõe, fragmenta, e sobrecarrega a atuação dos sujeitos sociais, impactando a sua capacidade de representação institucional e de participação em suas esferas de atuação política e social.

Impressões da pesquisa que estamos realizando junto às associações na cidade de Florianópolis corroboram esses desafios. A Ufeco (União Florianopolitana de Entidades Comunitárias), organização que reúne e representa as associações de moradores do município, conta com representação nos conselhos de saúde, educação, transporte, meio ambiente e habitação. Entre a lista de objetivos da entidade 
constam $^{29}$ : fortalecer a participação na vida associativa e na vida dos bairros de Florianópolis; assessorar a formação de novas associações; propor projetos de lei junto à Assembleia Legislativa; propor cursos de formação política em gestão comunitária e formação de lideranças; promover em conjunto com as entidades filiadas, projetos de lazer, cultura, teatro, cinema, esporte etc; acompanhar e defender o processo democrático-participativo do Plano Diretor de Florianópolis de acordo com o estabelecido pelo Estatuto da Cidade, inclusive em demandas judiciais se for necessário; fortalecer a participação no Fórum da cidade e estimular a formação de Fóruns regionais que discutam a cidade; defender o ensino fundamental público, a saúde universal, os serviços públicos essenciais à população, como o transporte; acompanhar e defender propostas democráticas de moradia popular, regularização fundiária, a constituição de Zeis (Zonas de Interesse Social); apoiar o movimento pela defesa 168 do meio ambiente, debatendo megaempreendimentos que se utilizam de áreas de preservação permanente; e participar das audiências públicas da Câmara de Vereadores acompanhando e debatendo a tramitação de projetos relevantes para o município de Florianópolis; além da representação nos Conselhos assinalados. O uso de diferentes repertórios e a ocupação de diferentes espaços institucionais acabam sobrecarregando as suas atividades, diante de importantes limites de recursos humanos e materiais. Além disso, a representação nos Conselhos acaba provocando uma espécie de monopólio da representação que impede uma maior pluralização da atuação coletiva na $\operatorname{cidade}^{30} \mathrm{e}$

\footnotetext{
${ }^{29}$ Objetivos que podem ser consultados na página da entidade na Internet: http:// www.ufeco.org.br.

${ }^{30} \mathrm{O}$ estudo de Almeida (2010) sobre os Conselhos Municipais de Saúde no Brasil, também aponta uma recusa ou resistência de alguns movimentos sociais de dividir atividades representativas com outros grupos ou associações, dificultando a renovação de lideranças.
} 
impactando negativamente na qualidade da representação no interior dos conselhos.

Diante de um quadro marcado por uma inflação de espaços de representação, parece pertinente o reconhecimento de uma "ecologia democrática das associações" (Warren, 2001), o que implica no reconhecimento de que nem todas as associações são boas para o exercício da representação conselhista, como muitas organizações que ocupam esses espaços de forma particularista ${ }^{31}$, ou aqueles movimentos sociais que, ao não abrirem mão da ocupação desses espaços de representação, limitam as possibilidades do exercício da representação democrática. Assim, as combinações - positivas e necessárias para uma representação democrática - entre participação e representação, são desafiadas constantemente pelas práticas políticas e sociais, e que estão inseridas em um contexto marcado por profundas desigualdades sociais.

Como vimos, associações e movimentos sociais estão ampliando os seus repertórios de atuação e assumindo papéis de representação nos espaços institucionais que foram criados em função das reivindicações e mobilizações sociais. Preenchendo um quadro mais amplo de espaços participativos e representativos, a representação conselhista constitui-se como mais um tipo de representação alternativa ao modelo eleitoral. Para cumprir com a sua vocação democrática, essa representação requer a construção de equivalentes de responsividade, e que em boa medida dizem respeito à sua capacidade de estabelecer relações com as práticas participativas, promovendo, por exemplo,

\footnotetext{
${ }^{31}$ Como certas organizações que prestam serviços sociais e que dependem dos Conselhos para a aprovação de recursos.
} 
encontros e fóruns de debates e discussão que permitam uma ativação dos setores que ocupam o outro lado do processo de representação. Assim, um dos pontos centrais dos debates sobre a pluralização da representação está localizado no reconhecimento de que representação e participação se complementam, superando abordagens que situam esses fenômenos de forma contraposta.

No entanto, as combinações, necessárias e positivas, entre participação e representação encontram problemas dados pela sobrecarga de atividades e as tensões movidas pela opção da atuação institucional, e que impactam tanto a capacidade de promover representação democrática no campo institucional, como a dinâmica própria da participação de associações e movimentos sociais. De fato, se olharmos o contexto mais amplo, essa modalidade de atuação institucional coloca mais um ingrediente no rol das atividades desenvolvidas por associações, especialmente no caso

170 dos movimentos sociais. Além da atuação em Conselhos, cuja agenda já é suficiente para consumir boa quantidade de tempo e energia participativa, há um conjunto muito mais vasto de atividades - institucionais e não institucionais - a cumprir, como audiências públicas, conferências, fóruns, assembleias, encontros, manifestações, conformando um complexo participativo que superpõe, fragmenta, e sobrecarrega a atuação dos sujeitos sociais.

Tendo em conta a pluralidade associativa e os pressupostos básicos da representação democrática, o trabalho apontou, resgatando alguns autores, um conjunto de requisitos associativos que, teoricamente, deveriam ser cumpridos por aquelas associações e organizações que reivindicam esse tipo de representação conselhista, como estrutura e recursos, objetivos públicos e práticas de responsividade, especialmente nas situações, a exemplo de vários Conselhos, em que os representados mais excluídos encontram-se desorganizados. Vários estudos apontam problemas e dificuldades da atua- 
ção representativa junto aos conselhos, indicando, entre outras variáveis e relações, uma sobrecarga dada pela combinação de diferentes, e algumas vezes contrapostos repertórios que envolvem lócus diferenciados de atuação, e que acabam minando possibilidades de alianças mais amplas, gerando fenômenos de sobrerrepresentação; e impactando os benefícios promovidos pela participação e representação.

\section{Lígia Helena Hahn Lüchmann}

é professora do Departamento de Sociologia e Ciência Política da UFSC.

\section{Referências bibliográficas}

ABERS, R. N.; KECK, M. E. 2008. "Representando a diversidade: estado, sociedade e 'relações fecundas' nos conselhos gestores". Caderno CRH, v.21, n.52, pp. 99-112.

ALMEIDA, D. R. 2010. "Representação política nos conselhos de saúde do Brasil”. Anais do III Seminário Nacional e I Seminário Internacional Movimentos Sociais Participação e Democracia. Florianópolis.

BAGGETTA, M. 2009. "Civil opportunities in associations: interpersonal interactions, governance experience and institutional relationships”. Social Forces, v. 88, n. 1, pp. 175-199.

BORBA, J.; LUCHMANN, L. H. H. 2010."A representação política nos Conselhos Gestores de Políticas Públicas”. Urbe, v. 2, n. 2, pp. 229-246.

CASTIGLIONE, D.; WARREN, M. 2006. "Rethinking democratic representation: eight theoretical issues". Disponível em $<$ http:/ /www. politics.ubc.ca/index.php?id=2516>. Acesso em 15/05/2011.

CHAMBERS, S.; KOPSTEIN, J. 2006. "Civil society and the state". In: DRYZEK, J; HONIG, B.; PHILLIPS, A. (orgs.) The Oxford handbook of political theory. Oxford: Oxford University Press.

COHEN J.; ROGERS, J. 1995. Associations and democracy. London: Verso. 1999. "Deliberation and democratic legitimacy". In: BOHMAN,

J: REGH, W. Deliberative democracy: essays on reason and politics.

Massachusetts: Institute of Tecnology.

DAHL, R. 1992. "The problem of civic competence". Journal of Democracy, v. 3, n. 4, pp.45-59.

DIANI, M. 1992. "The concept of social movement". The Sociological Review, n. 40 , pp. $1-25$. 
; BISON, I. 2010. "Organizações, coalizões e movimentos". Revista Brasileira de Ciência Política, n. 3, pp. 220-249.

DRYZEK, J.; NIEMEYER, S. 2008. "Discursive representation”. American Political Science Review, v. 102, n. 4, pp 481-493.

FISHKIN, J. 2010. "Response to critics of when the people speak: the deliberative deficit and what to do about it". The Good Society, v. 19, n. 1, pp. 68-76.

FUNG, A. 2003. Associations and democracy: between theories, hopes, and realities. Annual Review of Sociology, v. 29, pp. 515-559. ; WRIGHT, E. O. 2001. "Deepening democracy: Innovations in empowered participatory governance”. Politics $\mathcal{E}^{2}$ Society, v.29, n. 1, pp. 5-42.

GURZA LAVALLE, A; HOUTZAGER, P; CASTELLO, G. $2006 \mathrm{a}$. "Representação política e organizações civis. Novas instâncias de mediação e os desafios da legitimidade”. Revista Brasileira de Ciências Sociais, v. 21, n. 60, pp. 43-66.

—_ _ _ _ 2006b. "Democracia, pluralização da representação política e sociedade civil”. Lua Nova, n. 67, pp. 49-103. HIRST, P. 1994. Associative democracy: new forms of economic and social governance. Amherst: University of Massachusetts Press.

172 ISUNZA VERA; GURZA LAVALLE, A. 2010 (orgs.). La innovación democrática en América Latina: tramas y nudos de la representación, la participación y el control social. México: Centro de Investigaciones y Estudios Superiores en Antropología Social - Universidad Veracruzana.

LÜCHMANN, L. H. H. 2007. "A representação no interior das experiências de participação”. Lua Nova, n. 70, pp. 139-170.

McADAM, D.; TARROW, S.; TILLY, C. 2009. "Para mapear o confronto político”. Lua Nova, n.76, pp. 11-48.

McADAM, D; McCARTHY, J. D.; ZALD, M. N. 2008. "Introduction: opportunities, mobilizing structures, and framing processes - toward a synthetic, comparative perspective on social movements". In: McADAM, D; McCARTHY, J. D.; ZALD, M. N. Comparative perspectives on social movements. New York: Cambridge University Press.

MELUCCI, A. 2001. A invenção do presente: movimentos sociais nas sociedades complexas. Petrópolis: Vozes.

MONTANARO, L. 2009. The democratic legitimacy of self-appointed representatives. Tese de doutorado. Vancouver: University of British Columbia, Faculty of Graduate Studies, Political Science.

PAXTON, P. 2002. "Social capital and democracy: an interdependent relationship”. American Sociological Review, v. 67, n. 2, pp. 254-277. 
PITKIN, H. F. 1972. The concept of representation. Berkeley: University of California Press.

PUTNAM, R. 1996. Comunidade e democracia: a experiência da Itália moderna. Rio de Janeiro: Ed. da FGV.

REHFELD, A. 2006. "Towards a general theory of political representation”. The Journal of Politics, v. 68, n. 1, pp. 1-21.

ROBTEUTSCHER, S. 2005. Democracy and the role of associations. London/ New York: Routledge.

SAWARD, M. 2006. "The representative claim”. Contemporary Political Theory, v. 5, n. 3, pp. 297-318. 2009. "Authorisation and authenticity: representation and the unelected”. The Journal of Political Philosophy, v. 17, n. 1, 2009, pp. 1-22. SILVA, M. K. et al. 2010. "Cuando nuevos personajes dominan el escenario: recursos organizativos y relaciones de poder en el Consejo Nacional de Salud de Brasil". In: ISUNZA VERA; GURZA LAVALLE, A. (orgs.). La innovación democrática en América Latina: tramas y nudos de la representación, la participación y el control social. México: Centro de Investigaciones y Estudios Superiores en Antropología Social Universidad Veracruzana, pp. 247-282.

STOLLE, D.; ROCHON, T. R. 1998. "Are all associations alike? Member diversity, associational type, and the creation of social capital". American Behavioral Scientist, v. 42, n. 1, pp. 47-65.

TATAGIBA, L.; BLIKSTAD, K. 2010. “As eleições das organizações populares para o Conselho Municipal de Habitação de São Paulo: limites, potencialidades e tensões presentes nas imbricações do movimento de moradia de São Paulo com o campo político institucional”. Anais do III Seminário Nacional e I Seminário Internacional Movimentos Sociais Participação e Democracia. Florianópolis: UFSC.

TILLY, C. 2006. Regimes and repertoiries. Chicago: University of Chicago Press. URBINATI, N.; WARREN, M. 2008. The concept of representation in contemporary democratic theory. The Annual Review of Political Science, v. 11, pp. 387-412.

WARREN, M. 2001. Democracy and association. Princeton: Princeton University. 2008. "Citizen representatives". In: ; PEARSE, H. (orgs.). Designing deliberative democracy: The British Columbia Citizen's Assembly. New York: Cambridge University Press.

; PEARSE, H. 2008. H. "Introduction: democratic renewal and deliberative democracy". In: (orgs). Designing deliberative democracy: The British Columbia Citizen's Assembly. New York: Cambridge University Press. 
Associações, participação e representação: combinações e tensões

YOUNG, I. M. 1995. "Social groups in associative democracy". In:

COHEN, J.; ROGERS, J. Associations and democracy. London: Verso.

2006. "Representação política, identidade e minorias". Lua Nova, n. 67 , pp. 139-190. 